\title{
Water-induced Effects on the Hardness and Modulus of Contemporary Sealants Derived from Instrumented Indentation Testing (IIT)
}

\author{
Valeria Diener ${ }^{1}$, Spiros Zinelis ${ }^{2}$, Theodore Eliades ${ }^{3}$
}

\begin{abstract}
Aim: To compare the mechanical properties of four different types of contemporary fissure sealants before and after water storage employing a modern instrumented indentation testing (IIT) method.

Materials and methods: Four different types of materials used in everyday practice were deliberately selected. Fissurit (FIS) is a highly filled resin, Embrace (EMB) is a bisphenol A (BPA)-free unfilled resin, Helioseal (HEL) is an unfilled resin, and Riva Protect (RIV) is a glass-ionomer material. Six cylindrical specimens from each material were prepared ( $h: 3 \mathrm{~mm}, \varnothing: 15 \mathrm{~mm})$, and Martens hardness (HM), elastic modulus ( $\left.E_{I T}\right)$, elastic index $\left(\eta_{I T}\right)$, and Vickers hardness (HV) were determined employing an IIT machine according to International Organization for Standardization (ISO) 14577:2015. Then, the samples were stored in water at $37^{\circ} \mathrm{C}$ for 48 hours and measured again at the same surface. The mechanical properties tested (HM, $E_{T T}, \eta_{T T}$, and $\mathrm{HV}$ ) were statistically analyzed by two-way repeated measurements analysis of variance (ANOVA) employing materials and conditions as discriminating variables. Statistically significant differences were identified by Tukey's post hoc multiple comparison test. In all cases, a $95 \%$ level of significance was set $(p=0.05)$.

Results: Statistically significant differences in selected mechanical properties were allocated among materials tested. The artificial aging had a detrimental effect on $\mathrm{HM}, E_{\mathrm{T}}$, and $\mathrm{HV}$ apart from $\eta_{\mathrm{TT}}$ for FIS, EMB, and HEL. In contrast, no significant differences were identified for RIV before and after water storage for all aforementioned properties apart from $\eta_{1 T}$.

Conclusion: Significant differences were identified in mechanical properties among materials tested and thus differences in their clinical behavior are anticipated.

Clinical significance: This study contributes to the understanding of the mechanical properties of different dental sealants with respect to water contact, which may influence the choice by the therapist.

Keywords: Elastic index, Fissure sealants, Instrumented indentation testing, Martens hardness, Mechanical properties.

The Journal of Contemporary Dental Practice (2019): 10.5005/jp-journals-10024-2574
\end{abstract}

\section{INTRODUCTION}

Pits and fissures of teeth are known as susceptible areas for initial carious lesions. They are most common as pronounced occlusal reliefs of molars or deep pits on their buccal or palatal surfaces or foramina caeca on the palatal side of maxillary lateral incisors. Particularly, the period during the dental eruption is vulnerable, ${ }^{1}$ so that it can be inferred that it is children who are mostly affected. To encounter the decay, sealants were introduced decades ago and are recognized as a valid instrument of prevention. ${ }^{2-4}$ Since broad levels of the population are concerned, several dental associations published guidelines. ${ }^{2,5,6}$ Although some authors stated that sealing of fissures is underused, ${ }^{2,7}$ it has to be said that the preventive effect seems to be greater in high-risk children. ${ }^{8}$

Different sealing materials have been proposed so far: diversely compounded resin composites $^{9-11}$ or glass ionomers $^{12}$ to name the most common. However, it is important for the practitioner to have a convenient material, but since dental material must withstand high-bite forces ${ }^{13}$ and changing $\mathrm{pH}$ and temperatures, it is also crucial to find suitable products, which can endure an environment like the oral cavity. When it comes to hardness, in a laboratory study, it was found that self-adhesive restorative materials performed better in comparison with conventional sealants. ${ }^{14}$ Mechanical properties, especially hardness, are indicative of the fracture and wear resistance of different material types used for this purpose. Currently, different types of materials are available in the dental

\footnotetext{
${ }^{1,3}$ Clinic of Orthodontics and Pediatric Dentistry, Center of Dental Medicine, University of Zurich, Zuirch, Switzerland

${ }^{2}$ Department of Biomaterials, University of Athens, Athens, Greece

Corresponding Author: Theodore Eliades, Clinic of Orthodontics and Pediatric Dentistry, Center of Dental Medicine, University of Zurich, Zurich, Switzerland, Phone: +41 446343210, e-mail: theodore.eliades@zzm.uzh.ch

How to cite this article: Diener V, Zinelis S, et al. Water-induced Effects on the Hardness and Modulus of Contemporary Sealants Derived from Instrumented Indentation Testing (IIT). J Contemp Dent Pract 2019;20(6):653-656.

\section{Source of support: Nil}

Conflict of interest: None
}

market with the same indication (i.e., filled and unfilled resins, glass ionomers, and others). In addition, new technological advancements in experimental testing can provide a wide array of mechanical properties with a single indentation measurement based on instrumented indentation testing (IIT). The experimental setup of this testing is scrutiny described in ISO $14577-1 .{ }^{15}$ Although Vickers hardness and a few other mechanical properties have been sporadically tested in previous studies, to date there has been no comparison among the mechanical properties of different contemporary types of fissure sealant materials. Therefore, the aim 
of this study was to compare the mechanical properties as provided by a modern testing methodology (IIT) among different types of fissure sealant materials used in contemporary pediatric dentistry. The null hypothesis was that the mechanical properties tested will show statistically significant differences among the different types of materials tested.

\section{Materials and Methods}

This study was conducted in the Clinic of Orthodontics and Pediatric Dentistry, Center of Dental Medicine, University of Zurich in Switzerland.

Four different materials were tested in this study. The brand names of the manufacturers and material types are presented in Table 1. Fissurit $F X(F I S)$ is a resin composite with a high percentage of fillers. Embrace (EMB) Wetbond is an unfilled resin and free of bisphenol A (BPA). Helioseal $\mathrm{F}$ (HEL) is an unfilled resin. Riva Protect (RIV) is a glass-ionomer material.

Six cylindrical specimens from each material were prepared employing cylindrical Teflon molds ( $h: 3 \mathrm{~mm}$ and $\varnothing: 15 \mathrm{~mm}$ ) placed on transparent cellulose strips. The molds were filled up with each material, covered with cellulose strips, and photopolymerized with slightly overlapping irradiation (20 seconds each) with a LED curing unit (Radii plus, SDI, Victoria, Australia).

The mechanical properties tested were determined employing an IIT machine (ZHU2.5/Z2.5 plus test Xpert software, Zwick/Roell, Ulm, Germany) according to ISO 14577. Five force-indentation depth curves were recorded from the directly exposed surfaces of each sample employing a Vickers indenter, $19.6 \mathrm{~N}$ load, and 2 seconds dwell time. The parameters determined according to mathematical formulas provided by ISO 14577 were Martens hardness (HM), elastic modulus $\left(E_{\mid T}\right)$, and elastic index defined as the plastic to elastic ratio of indentation work $\left(\eta_{T_{T}}\right)$. Vickers hardness was determined by measuring the diagonal length of indentation with the optical system employing a $40 \times$ magnification lens. The mean value from each specimen was used to characterize the specimen itself.

Then, the samples were stored in water at $37^{\circ} \mathrm{C}$ for 48 hours and measured again at the same surface.

\section{Statistical Analysis}

The mechanical properties tested (HM, $E_{\mathrm{IT}}, \eta_{\mathrm{IT}}$, and $\mathrm{HV}$ ) were statistically analyzed by two-way repeated measures ANOVA employing materials and conditions (as set and after water storage) as discriminating variables. Statistically significant differences were identified by Tukey's post hoc multiple comparison test. In all cases, a $95 \%$ level of significance was set $(p=0.05)$.

\section{Results}

Figure 1 shows representative force indentation curves of all materials tested before and after artificial aging where higher indentation depth denotes a softer material. The mean values and standard deviations of $\mathrm{HM}, E_{\mathrm{IT}}$, elastic index, and $\mathrm{HV}$ are presented in Table 2. FIS and RIV showed significantly higher HM with the former illustrating significantly higher HM compared to EMB and HEL. RIV(A) showed significantly higher HM after aging followed by $\operatorname{FIS}(A), \operatorname{HEL}(A)$, and $\operatorname{EMB}(A)$. All materials showed significantly inferior $\mathrm{HM}$ after aging except for RIV. The latter illustrated a higher elastic modulus $\left(E_{I T}\right)$ followed by FIS and EMB, while HEL showed the lowest values. The same classification was maintained after artificial aging while only FIS and EMB showed lower values after aging. RIV exhibited a lower elastic index $\left(\eta_{1 T}\right)$ compared to FIS, EMB, and HEL, and the same classification was maintained among materials after aging. Only RIV showed a significantly increased value of elastic index after aging, while no differences were allocated for the rest materials. Statistically significant differences in HV were identified among materials tested before and after aging, while all materials except RIV showed significantly lower HV after aging.

\section{Discussion}

According to the experimental results, the null hypothesis must be accepted as the mechanical properties were indeed varied among materials tested. The materials were deliberately selected as a representative from four different types of materials used in everyday practice in contemporary pediatric dentistry. FIS is a highly filled resin, EMB is a BPA-free unfilled resin, $\mathrm{HEL}$ is an unfilled resin, and RIV is a glass-ionomer material.

In this study, both HM and HV are deliberately included due to their methodological differences. HM is calculated based on force, indentation depth, and impression surface recorded during the force indentation depth curve. HM is determined automatically by software without any user interference. Historically, this property has been introduced as universal hardness, but later has been widely accepted as Martens hardness. Contrarily, the traditional HV values are determined by measuring the diagonal length of resulting impression and thus its accuracy is dependent on rebound of materials, user's perception, resolution of the optical system, and others. ${ }^{16}$ However, IIT results are scarcely found in dental literature for fissure sealants and thus the expression of HV was kept for comparison purposes with literature data.

There are a few studies reporting the HV values of different types of materials tested but only one with HEL tested in this study. There is only one study with IIT results but with different materials from the current study. The HV value of HEL was found to be close to previous reported data for the same product by Bevilacqua et al. after curing samples with a halogen and a plasma arc curing unit, respectively (28 and $30 \mathrm{HV}) .{ }^{17}$ Kuşgöz et al. published a study in which after 24 hours of aging in water, a bisphenol A-glycidyl methacrylate (BIS-GMA) unfilled resin (Clinpro 3M, ESPE) showed $21 \mathrm{HV}$, while a glass-ionomer material (Fugi Triage, GC Corporation) demonstrated $65 \mathrm{HV}$ although the differences with the current results should be appended to different material formulations and filler loading. ${ }^{18} \mathrm{HM}$ values have not been reported in the dental literature so far. In a study of Magni et al.,

Table 1: Brand name, manufacturer, material type, and code of material tested

\begin{tabular}{llll}
\hline Brand name & Manufacturer & Code \\
\hline Fissurit FX & Voco, Cuxhaven, Germany & Resin composite filler content: 55\% w/w & FIS \\
& & & \\
Embrace Wetbond & Pulpdent Corporation, Watertown, MA, USA & Unfilled resin and BPA free & EMB \\
Helioseal F & Ivoclar Vivadent, Schaan, Lichtenstein & Unfilled resin & HEL \\
Riva protect & SDI, Victoria, Australia & Glass-ionomer & RIV \\
\hline
\end{tabular}



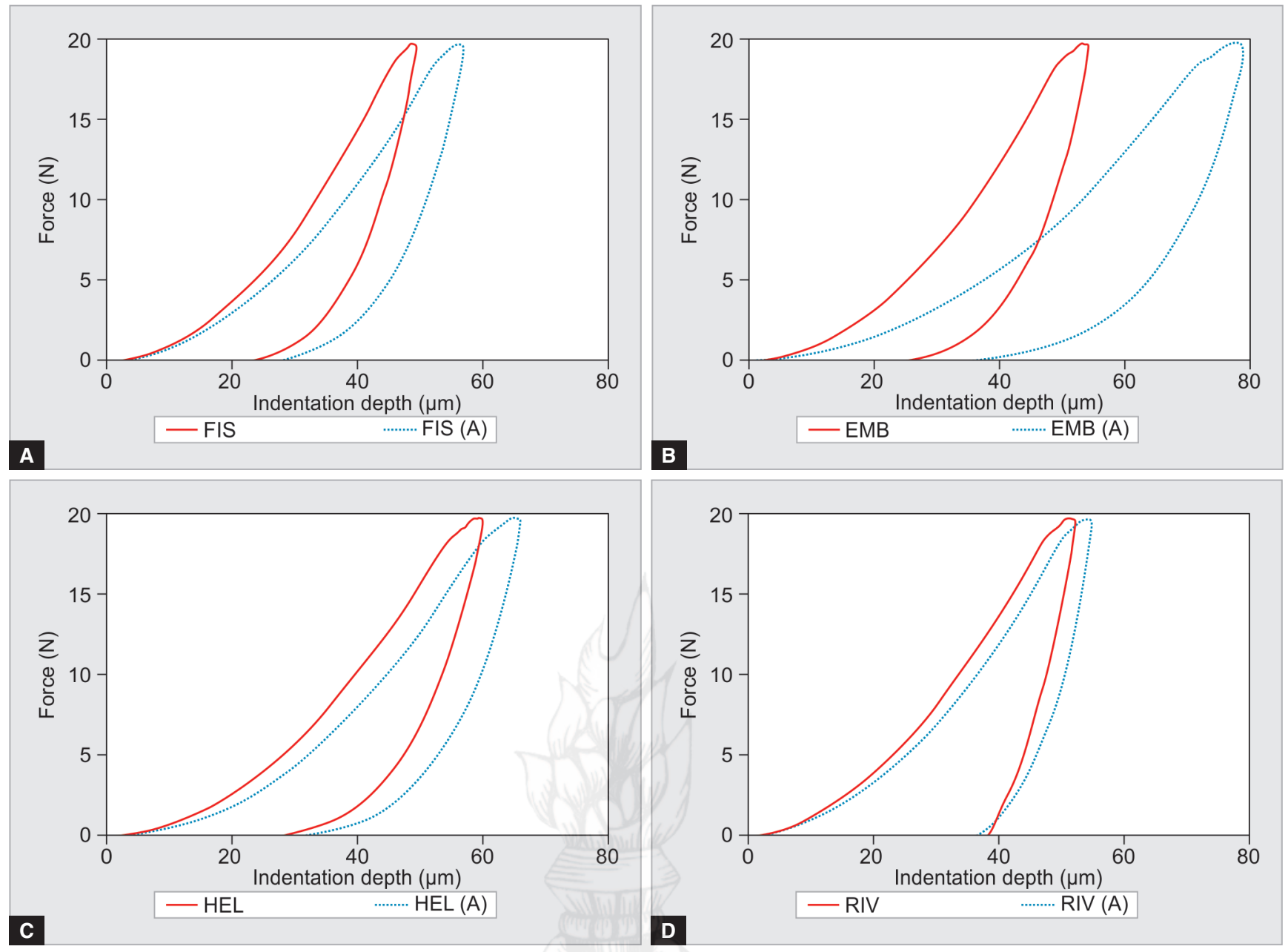

Figs 1A to D: Representative force-indentation depth curves of all materials tested before and after water storage. (A) Fissurit; (B) Embrace, (C) Helioseal; and (D) Riva Protect

Table 2: Mean values and standard deviations in parentheses of Martens hardness (HM), indentation modulus $\left(E_{\mathrm{IT}}\right)$, and elastic index $\left(\eta_{\mathrm{IT}}\right)$ of all materials tested before and after artificial aging $(n=10)$

\begin{tabular}{|c|c|c|c|c|c|c|c|c|}
\hline \multirow[b]{2}{*}{ Material } & \multicolumn{2}{|c|}{ Martens hardness (HM) ( $\left.\mathrm{N} / \mathrm{mm}^{2}\right)$} & \multicolumn{2}{|c|}{ Elastic modulus $\left(E_{I T}\right)(G P a)$} & \multicolumn{2}{|c|}{ Elastic index $\left(\eta_{I_{T}}\right)(\%)$} & \multicolumn{2}{|c|}{ Vickers hardness (HV) } \\
\hline & As set & After aging & As set & After aging & As set & After aging & As set & After aging \\
\hline FIS & $317(6)^{\mathrm{a} 1}$ & $237(29)^{\mathrm{ab} 2}$ & $8.5(0.2)^{\mathrm{a} 1}$ & $6.8(0.8)^{\mathrm{a} 2}$ & $39.4(0.6)^{a 1}$ & $37.7(2.6)^{\mathrm{a} 1}$ & $40(2)^{a 1}$ & $33(2)^{\mathrm{a} 2}$ \\
\hline EMB & $273(23)^{\mathrm{bc} 1}$ & $133(6)^{\mathrm{b} 2}$ & $8.1(1.0)^{\mathrm{a} 1}$ & $4.5(0.3)^{b 2}$ & $36.5(2.9)^{\mathrm{a} 1}$ & $37.2(5.9)^{\mathrm{a} 1}$ & $33(1)^{b 1}$ & $13(1)^{\mathrm{b} 2}$ \\
\hline HEL & $211(18)^{c 1}$ & $179(13)^{c 2}$ & $5.5(0.5)^{\mathrm{b} 1}$ & $5.0(0.3)^{c 1}$ & $39.3(1.2)^{\mathrm{a} 1}$ & $37.5(0.8)^{\mathrm{a} 1}$ & $26(1)^{c 1}$ & $22(1)^{\mathrm{c} 2}$ \\
\hline RIV & $299(23)^{\mathrm{ac} 1}$ & $286(34)^{\mathrm{d} 1}$ & $10.0(0.6)^{\mathrm{c} 1}$ & $9.2(1.0)^{\mathrm{d} 1}$ & $24.7(1.6)^{\mathrm{b} 1}$ & $28.2(2.1)^{\mathrm{b} 2}$ & $39(1)^{d 1}$ & $40(1)^{d 1}$ \\
\hline
\end{tabular}

Same alphabetic superscripts denote mean values without statistical differences among different materials (among rows) and same numeric superscripts before and after storage (between columns)

the elastic modulus and elastic index of RIC are similar to values $\left(E_{\mathrm{IT}}=12.3 \pm 2.1\right.$ and $\eta_{\mathrm{IT}}=34.8 \pm 3.3$ ) presented for a conventional glass ionomer (lonofil Molar, VOCO). ${ }^{19}$

Both HM and HV classification of materials after curing (Table 2) can be appended to the differences in their chemical formulations. FIS as a heavy-loaded resin material showed the highest HM and $\mathrm{HV}$ values followed by the unfilled resin $(\mathrm{HEL})$, while EMB demonstrated the lowest values as unfilled and BPA-free resin as the latter provides rigidity due to its molecular structure. Storage in water before testing is a general guideline by ISO 11405:2015, and it is used to indicate materials that can successfully withstand the wet environment. ${ }^{20}$ Although the properties tested after curing represent the initial values of material itself, the values after water storage are considered to be more representatives to intraoral conditions. The mechanical properties derived by IIT have important clinical implications. In both expressions, HM or HV hardness is the primary factor for wear and abrasion resistance and thus materials with higher hardness are more suitable for this type of application where stresses developed due to occlusion forces or the direct contact of bolus of food at the restoration surface. Higher elastic modulus is also beneficial for this application, as materials with higher modulus can withstand the same stresses with smaller dimensions, which is an important property for materials used in thin layers. Another consequence is that for a given volume, 
materials with higher modulus can resist higher stresses. The elastic index is indicative of the ductility/brittleness of the materials. The higher the elastic index, the higher the brittleness and thus the materials with a higher elastic index are more vulnerable to the chipping phenomenon. Based on the aforementioned comments and from a pure mechanical standpoint, RIV combines after water storage the best combination of properties tested showing the highest hardness and elastic modulus and lower brittleness among the materials tested. The time frame of the samples stored in water was only 48 hours before the hardness was tested. Hence, it does not represent in vivo situation where a sealant persists in the oral cavity for several months or years. Another limitation is that the study did neither consider the intermittent temperature changes nor the mechanical abrasion or molecular biological processes taking place under natural conditions. However, more experimental research should be exerted on application-related properties including a broader array of physical, chemical, and mechanical properties and, if possible, combined clinical data before a final decision for the most suitable material type for this application can be decided.

\section{Conclusion}

The fissure sealant materials tested showed significant differences in the mechanical properties tested.

Water storage has a detrimental effect on all mechanical properties tested apart from the elastic index. Contrarily, the properties of glass-ionomer materials tested remained unaffected except for the elastic index.

Glass ionomer showed the best combination of mechanical properties after water storage among all materials included in this study.

\section{References}

1. Lynch RJM. The primary and mixed dentition, post-eruptive enamel maturation and dental caries: a review. Int Dent J 2013;63 Suppl 2:3-13. DOI: 10.1111/idj.12076.

2. Wright JT, Crall JJ, et al. Evidence-based clinical practice guideline for the use of pit-and-fissure sealants: a report of the American Dental Association and the American Academy of Pediatric Dentistry. J Am Dent Assoc 2016;147(8):672-682.e12. DOI: 10.1016/j.adaj.2016.06.001.

3. Welbury R, Raadal M, et al. EAPD guidelines for the use of pit and fissure sealants. Eur J Paediatr Dent 2004;5(3):179-184.

4. Ahovuo-Saloranta A, Forss $\mathrm{H}$, et al. Pit and fissure sealants versus fluoride varnishes for preventing dental decay in the permanent teeth of children and adolescents. Cochrane Database Syst Rev 2016;1:CD003067. DOI: 10.1002/14651858.CD003067.pub4.

5. Kühnisch J, Ekstrand KR, et al. Best clinical practice guidance for management of early caries lesions in children and young adults: an
EAPD policy document. Eur Arch Paediatr Dent 2016;17(1):3-12. DOI: 10.1007/s40368-015-0218-4.

6. Nunn JH, Murray JJ, et al. British Society of Paediatric Dentistry: a policy document on fissure sealants in paediatric dentistry. Int J Paediatr Dent 2000;10(2):174-177.

7. Simonsen RJ. Pit and fissure sealant: review of the literature. Pediatr Dent 2002;24(5):393-414.

8. Ahovuo-Saloranta A, Forss $\mathrm{H}$, et al. Sealants for preventing dental decay in the permanent teeth. Cochrane Database Syst Rev 2013;3:CD001830. DOI: 10.1002/14651858.CD001830.pub4.

9. Kucukyilmaz E, Savas S. Evaluation of different fissure sealant materials and flowable composites used as pit-and-fissure sealants: a 24 month clinical trial. Pediatr Dent 2015;37(5):468-473.

10. Prabhakar AR, Murthy SA, et al. Comparative evaluation of the length of resin tags, viscosity and microleakage of pit and fissure sealants an in vitro scanning electron microscope study. Contemp Clin Dent 2011;2(4):324-330. DOI: 10.4103/0976-237X.91797.

11. Sen Tunc E, Bayrak S, et al. Evaluation of microtensile bond strength of different fissure sealants to bovine enamel. Aust Dent J 2012;57(1): 79-84. DOI: 10.1111/j.1834-7819.2011.01639.x.

12. Naoum SJ, Mutzelburg PR, et al. Reducing composite restoration polymerization shrinkage stress through resin modified glassionomer based adhesives. Aust Dent J 2015;60(4):490-496. DOI: 10.1111/adj.12265.

13. de Abreu RAM, Pereira MD, et al. Masticatory efficiency and bite force in individuals with normal occlusion. Arch Oral Biol 2014;59(10): 1065-1074. DOI: 10.1016/j.archoralbio.2014.05.005.

14. Eliades A, Birpou E, et al. Self-adhesive restoratives as pit and fissure sealants: a comparative laboratory study. Dent Mater 2013;29(7): 752-762. DOI: 10.1016/j.dental.2013.04.005.

15. International Organization for Standardization. ISO 14577-1:2015 metallic materials - instrumented indentation test for hardness and materials parameters - part 1: test method [internet]. Geneva: ISO; published 2015-07. Available from: https://www.iso.org/ standard/56626.html.

16. Shahdad SA, McCabe JF, et al. Hardness measured with traditional Vickers and Martens hardness methods. Dent Mater 2007;23(9): 1079-1085. DOI: 10.1016/j.dental.2006.10.001.

17. Bevilacqua $L$, Sossi $A$, et al. Comparative evaluation of the microhardness of 4 dental sealants. Eur J Paediatr Dent 2007;8(4): 179-182.

18. Kuşgöz A, Tüzüner T, et al. Conversion degree, microhardness, microleakage and fluoride release of different fissure sealants. J Mech Behav Biomed Mater 2010;3(8):594-599. DOI: 10.1016/j.jmbbm.2010.07.008.

19. Magni E, Ferrari $M$, et al. Evaluation of the mechanical properties of dental adhesives and glass-ionomer cements. Clin Oral Investig 2010;14(1):79-87. DOI: 10.1007/s00784-009-0259-3.

20. International Organization for Standardization. ISO/TS 11405:2015 dentistry - testing of adhesion to tooth structure [internet]. Geneva: ISO; published 2015-02. Available from: https://www.iso.org/ standard/62898.html. 